\title{
Reducing the nonconforming products by using the Six Sigma method: A case study of a polyes- ter short cut fiber manufacturing in Indonesia
}

\author{
Oky Syafwiratama ${ }^{a^{*}}$, Mohammad Hamsal ${ }^{\mathrm{b}}$ and Humiras Hardi Purba ${ }^{\mathrm{a}}$
}

${ }^{a}$ Mercu Buana University, Jakarta, 11650, Indonesia ${ }^{b}$ Binus University, Jakarta 10270, Indonesia

\section{H R O N I C L E}

Article history:

Received: June 1, 2016

Received in revised format: No-

vember 16, 2016

Accepted: November 29, 2016

Available online:

December 3, 2016

\section{Keywords:}

Six Sigma

Nonconforming products

Polyester shortcut fiber

Process improvement

Quality

\section{A B S T R A C T}

Polyester short cut fiber is a textile industry which is rarely explored or researched. This research explains the necessary steps of improvement using Six Sigma method to reduce the nonconforming products in a polyester short cut fiber manufacturing in Indonesia. An increased nonconforming products in the shortcut fiber production process created some quality problems from January to May, 2015. Define, measure, analysis, improve, control (DMAIC) steps were implemented to determine root cause of the problems and to improve production process using statistical approach. The results of Six Sigma improvement has indicated that the process capability was increased from 2.2 to 3.1 sigma, savings $\$ 18,394.2$ USD per-month.

2017 Growing Science Ltd. All ightsicserved.

\section{Introduction}

Polyester is an industrial major which has the biggest market share both in the Indonesian market and the export commodities. Shortcut fiber is a variant textile product from polyester materials which has the biggest profit for the export commodities. Few textile companies that manufactured polyester short cut fiber due to tightness of the quality are expected. Shortcut fibers are short fibers used in many paper applications such as security paper, specialty paper, filter paper and wallpaper. The fiber improves properties such as tear, tensile, and burst strength (Goettmann \& Boylan, 1992).

Nonconforming product is a big problem in the production process which decreases the yield of good unit, resulting from product nonconformity with established specification due to manufacturing variability (Djamaludin et al., 1994). The highest percentage of nonconforming products is due to quality issue. The present survey reports a task completed to find out the roots and causes of quality failure using Six sigma method. Sig Sigma is a systematic method that has been widely used to reduce varia-

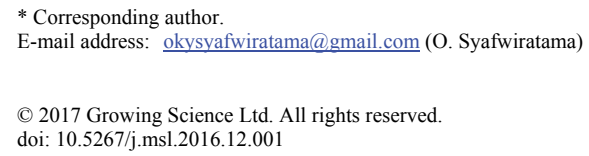


tion process and to improve the product quality through root cause analysis of the problem and improved quality using design of experiments. (Sonphuak \& Rojanarowan, 2013; Sahoo et al., 2008; Aksoy \& Orbak, 2009; Sokovic et al., 2006).

\section{Literature review}

Product quality is a basic guarantee of a manufacturing company to the customer and an important point in survival. Quality management is an important point for the enterprises management and should be of high concern (Mu et al., 2013). Defective product is defined as any nonconformity of products output to customer specifications or output that has the potential unfulfilled customer specifications. By reducing defects, the company will strengthen in the competitive advantage. Company will continue to reduce defects as it can increase production cost due to rework and scrap. Many organizations have implemented Six Sigma in reducing or eliminating defects, made quality improvement and cost savings in the manufacturing industry. Six Sigma is a systematic method for process improvement strategy that uses a statistical approach and scientific method in reducing defect rate defined by the customer (Croft et al., 2012).

Six Sigma was developed by a Motorola engineer (Bill Smith) in the middle of 1980s. Six Sigma provided results in the business process marked by revival of Motorola and ultimately won Malcom Baldridge National Quality Awards in the 1988 (Snee, 2010).

Six Sigma will continue to be one of initiatives to improve the process in the future. Top management should concentrate on improving the process and not just thinking for calculating disability. In a survey conducted by DynCorp (Mekong Capital Ltd) in 2004, the following results were found: (i) Around 22 percent of US companies implemented Six Sigma, (ii) 38.2 percent of the companies using Six Sigma was in service industry, (iii) 49.3 percent companies using Six Sigma was in manufacturing industry and 12.5 percent were others. (iv) Six Sigma maintained a higher rating than the quality management system and other process improvement tools to achieve maximum results (Zare, 2011).

Six Sigma methodology is accomplished based on two approaches; DMAIC and DMADV. DMAIC (define, measure, analyze, improve and control) is used to make improvement and to reduce defect products (Dambhare et al., 2013). By using Pareto Chart analysis we can define the highest cause of rejection. In measure phase, the customers' requirement is important, where by Critical to Quality (CTQ) will be identified to ensure all study meets the customers' requirements. To perform the root cause problem we may use FTA and failure mode and effect analysis (FMEA). Each issue can be defined and measured using statistical method of data collection. Analysis can be performed using a variety of statistical techniques such as Chi-Square, Regression Analysis, ANOVA, etc. Data processing can be performed using Minitab software for various types of projects undertaken. In improvement phase, all output will act according to the result in analysis phase. Improvement section will define the risk and other alternatives are considered to solve the problem. In the final stage, control phase will ensure all results and outputs are continually improved (Kairualazam et al., 2014).

DMAIC is the classic six sigma problem solving process. This approach is to be applied with an existing condition, steady state process or product offering. The variation found from the customer specifications either in a product or process the primary problem and these variations could be in many forms. DMAIC resolves issues of defects, deviations form a target, excess time or cost and the deterioration. DMAIC identifies the key requirement, deliverables, tasks and standard tool for a project team to utilize when tackling a problem. The DMAIC methodology uses a process step structure and steps generally are sequential (Nithyanandam et al., 2014).

Six Sigma DMAIC is an approach that refers to the quality improvement strategy. As the backbone of Six Sigma, DMAIC approach provides sustainable defect performance free and long term quality competitiveness (Rao et al., 2015). Sigma is a letter in Greek alphabet which means standard deviations of the expected results. Standard deviation can be defined as the ratio between expected results within a group procedures against the ones which are not succeed. Measurement of standard deviations describe the defect rate or exception that can be calculated (Ketan \& Nassir, 2016). Six Sigma combines the 
intelligence organization and statistical tools for conducting improvements in obtaining more effective and efficient results. Success factors of Six Sigma depends on elements of the models to be implemented. Six Sigma aims to reduce defect rate of production processes, products or services to the level of 3.4 defects per million opportunities (DPMO) (Kumaravadivel et al., 2013).

\section{Table 1}

Six Sigma Chart

\begin{tabular}{cccc}
\hline Specification Limit & Percent Conformance & Nonconforming rate & Process Capability \\
\hline $1 \sigma$ & 68.7 & 317,300 & 0.33 \\
$2 \sigma$ & 95.45 & 485,500 & 0.67 \\
$3 \sigma$ & 99.73 & 2700 & 1 \\
$4 \sigma$ & 99.9937 & 63 & 1.33 \\
$5 \sigma$ & 99.99994 & 0.57 & 1.67 \\
$6 \sigma$ & 100 & 0.002 & 2 \\
\hline
\end{tabular}

The main idea of Six Sigma is to design the processes to gain a very high capability process in favor of zero defects (Kwak et al., 2006). Some facts are considered to illustrate why obtained level of 99 percent of quality is no longer enough (McClusky, 2000). First, on mail delivery, reaching the quality of 99 percent means there are 10,000 mails are lost in every hour. Second, landing at airports for the quality of 99 percent means there are two unsafe landed aircrafts in every hour. Third, medical surgical for the quality of 99 percent means there are 500 patients undergoing surgical errors in every week. Fourth, power plant operations for the quality of 99 percent implies seven hours blackout within a month.

According to these facts, by considering an obtained quality level for only 99 percent or 1 percent of defect levels on such cases in manufacturing industries can potentially lead to fatalities. Hence, for gaining the target of quality level of 99.9996 percent or free-defects, an organization requires both flexibility and discipline in solving problems using statistical approach rather than using simple intuition or by trial and error (Pacheco, 2014). Implementation of Six Sigma's method is more valuable due to its contribution to the science and practice for particularly reduces waste and provides added values. Six Sigma allows users to identify waste, eliminates defects, increases profit margin, satisfies customers, encourages employee commitment and satisfaction as well as expands businesses (Patil et al., 2015).

\section{Research methodology}

The present study uses Six Sigma DMAIC as a method to reduce short cut fiber nonconforming product. In the define phase, we use Pareto Diagram to stratify potential factors increase nonconforming products. Sigma level measure for detecting current capabilities of short cut fiber and baseline production process are shown by four block diagram. Based on current capabilities, we analyze how some factors could increase nonconforming products. Field inspection and brainstorming are conducted to determine the vital factors. After knowing the vital factors, we perform some tests using one way ANOVA to determine the effect of vital factors. If the vital factors influence on the problem, then we perform design of experiment using Two Level Factorial Design (Design Factorial). Design of experiment is conducted to obtain vital factors optimal settings.

\section{Process improvement}

\subsection{Define}

From the January to May, 2015 production increased nonconforming products, 27.54 percent products could not be sold as the first grade in that period. Details of production yield, conforming and nonconforming products data are shown in Table 2 . 
Table 2

Achievement products of short cut fiber over the period January-May, $2015(\mathrm{~kg})$

\begin{tabular}{cccc}
\hline Month & Yield & Conforming Products & Nonconforming Product \\
\hline Jan & 290,700 & 209,700 & 81,000 \\
Feb & 388,800 & 262,350 & 126,450 \\
Mar & 189,000 & 173,250 & 15,750 \\
Apr & 76,050 & 42,750 & 33,300 \\
May & 427,950 & 306,450 & 121,500 \\
\hline Total & $1,372,500$ & 994,500 & 378,000 \\
\hline
\end{tabular}

Based on nonconforming product, some data are collected to analyze causative factors. Causative factors are stratified by the Pareto Diagram to view the main cause of the problem.

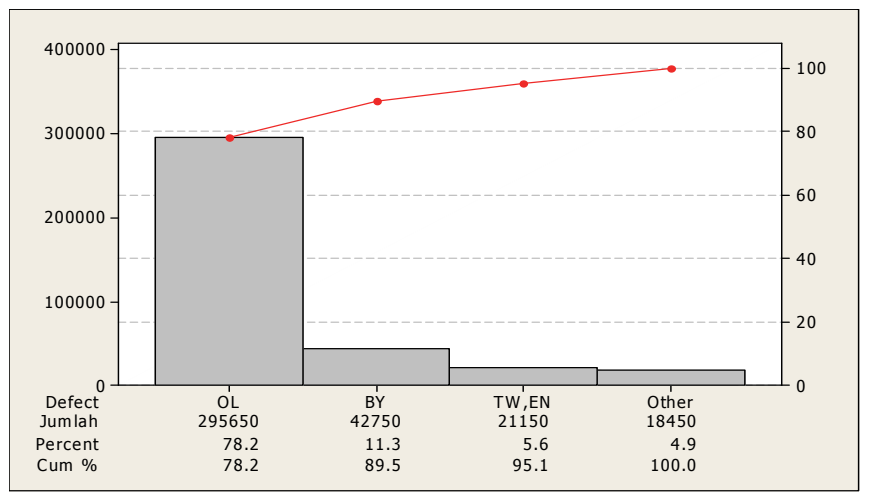

Fig. 1. Pareto Diagram of Nonconforming Products Causative Factor

Stratified results by Pareto Diagram indicates 78.2 percent causative factors of nonconforming products is Over Length. Over length is nonconformities length products when the results of short cut fiber cutting are more than targets. Shortcut fiber has four types of length products $(5,6,10$ and 12 millimeters) with a 60 percent deviation tolerance for any length product.

\subsection{Measurement}

In this stage we define measurement indicators, collect the necessary data, look for sources of variation and determine the current level of sigma (Tchidi et al., 2012). To determine the current state of the short cut fiber capability all defect per opportunity (DPO), defect per million opportunity (DPMO), yield ( $\left.\mathrm{Y}_{\mathrm{NA}}\right)$, Long term capability (Zlt) and short term capability (Zst) or sigma level are measured. Details of defect over length in the short cut fiber capability are shown in Table 3.

Table 3

Process capability on the January - May 2015

\begin{tabular}{cccccccc}
\hline Month & OL & Sample & DPO & DPMO & Y $_{\text {NA }}$ & $($ Zlt $)$ & (Zst) \\
\hline Jan & 628 & 1974 & 0.318 & $318,135.76$ & 0.682 & 0.47 & 1.97 \\
Feb & 613 & 2431 & 0.252 & $252,159.61$ & 0.748 & 0.67 & 2.17 \\
Mar & 69 & 814 & 0.085 & $84,766.58$ & 0.915 & 1.37 & 2.87 \\
Apr & 269 & 680 & 0.396 & $395,588.24$ & 0.604 & 0.26 & 1.76 \\
May & 743 & 3138 & 0.237 & $236,775.02$ & 0.763 & 0.72 & 2.22 \\
Mean & 464.4 & 1807.4 & 0.257 & $257,485.04$ & 0.743 & 0.7 & 2.2 \\
\hline
\end{tabular}

Table 3 shows the average short cut fiber capability in the amount of 2.20 sigma with 485.04 DPMO (defect per million opportunities). Baseline production, both of control and technology are depicted on the four block diagram in Fig. 2.

$$
\mathrm{Z} \text { shift }=Z_{\mathrm{ST}}-\mathrm{Z}_{\mathrm{LT}}
$$




$$
=2.20-0.70=1.5
$$

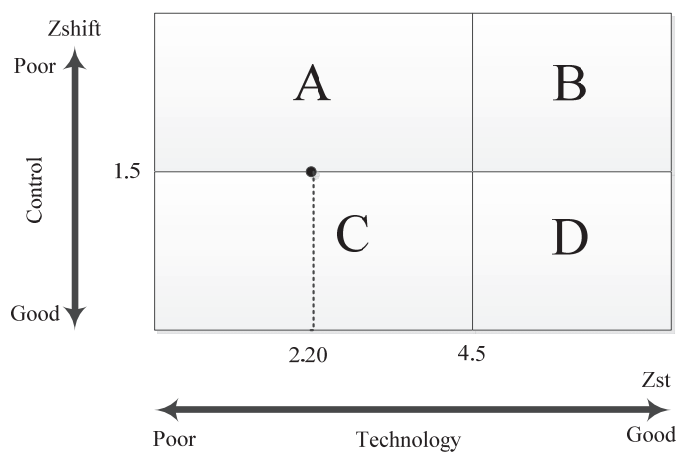

Fig. 2. Baseline production of short cut fiber

Fig. 2 shows the production process stays on $\mathrm{C}$ block and obviously the mean process production is still weak in the form technology.

\subsection{Analyze}

Analyses are carried out on the vital factors that cause the occurrence of over length. Based on finding of field check carried out brainstorming and obtained vital factors causes over length. Table 4 shows the results of our survey.

\section{Table 4}

Testing of vital factors in the drawing area

\begin{tabular}{|c|c|c|c|c|c|}
\hline Vital Factor & Item & Position & Unit & Current $(\mu 1)$ & Setting $(\mu 2)$ \\
\hline \multirow{9}{*}{ Tow passing } & \multirow{3}{*}{ Comb guide before DOB } & Outer & Millimeter & 40 & 75 \\
\hline & & Middle & Millimeter & 36 & 91 \\
\hline & & Inner & Millimeter & 40 & 75 \\
\hline & \multirow{3}{*}{ Comb guide after DOB } & Outer & Millimeter & 75 & 88 \\
\hline & & Middle & Millimeter & 80 & 90 \\
\hline & & Inner & Millimeter & 75 & 88 \\
\hline & \multirow{3}{*}{ Comb guide after tensioner } & Outer & Millimeter & 95 & 105 \\
\hline & & Middle & Millimeter & 98 & 110 \\
\hline & & Inner & Millimeter & 95 & 105 \\
\hline $\begin{array}{c}\text { Press roll RS } \\
\text { IV }\end{array}$ & & & $\mathrm{Kg} / \mathrm{cm}^{2}$ & 4 & 3.5 \\
\hline
\end{tabular}

Hypothesis testing: $\left(\mathrm{H}_{0}: \mu 1=\mu 2, \mathrm{H}_{1}: \mu 1 \neq \mu 2\right)$

The results of data processing using Minitab software shows P-Value of 0.017 , which means vital factors have an influence on the over length. Table 5 shows the results of vital factors.

\section{Table 5}

Testing of vital factors in the crimper area

\begin{tabular}{cccc}
\hline Vital Factor & Unit & Current $(\mu 1)$ & Setting $(\mu 2)$ \\
\hline NR Pressure & $\mathrm{Kg} / \mathrm{cm}^{2}$ & 1.2 & 1 \\
Gear reel scale & $\mathrm{Scale}$ & 7.8 & 7 \\
Speed Conveyor CDS & $\mathrm{M} / \mathrm{min}$ & 0.45 & 0.39 \\
\hline
\end{tabular}

Hypothesis testing $\left(\mathrm{H}_{0}: \mu 1=\mu 2, \mathrm{H}_{1}: \mu 1 \neq \mu 2\right)$

Processing data result by Minitab shows that the mean vital factor influences on the over length. 
Table 6

Testing of Vital Factors in the Cutter Area

\begin{tabular}{cccc}
\hline Vital Factor & Unit & Current $(\mu 1)$ & Setting $(\mu 2)$ \\
\hline Cutter - Feed roll speed & - & $\mathrm{H}$ & $\mathrm{L}$ \\
H-guide - Rotor distance & $\mathrm{Mm}$ & 15 & 5 \\
Press roll - rotor distance & $\mathrm{Mm}$ & 4.5 & 3 \\
\hline
\end{tabular}

Hypothesis testing $\left(\mathrm{H}_{0}: \mu 1=\mu 2, \mathrm{H}_{1}: \mu 1 \neq \mu 2\right)$

Again, the results of Minitab processing data shows $\mathrm{P}-$ Value is 0.007 , which is less than $\alpha\left(\mathrm{H}_{0}\right.$ did not accept), and we can conclude the vital factors influence on the over length.

\subsection{Improvement}

Improvement phase has also been conducted to determine the ideal setting on the crimper and cutter area using two level factorial design by Minitab software.

\section{Design of Experiment in the Crimper Area}

Independent variable ( $\mathrm{X}_{1}$ : Nip roll pressure, $\mathrm{X}_{2}$ : Gear reel scale, $\mathrm{X} 3$ : Coveyor CDS speed), Response variable (Y: DPO of over length).

\section{Table 7}

Design of experiment crimper area

\begin{tabular}{cccccccc}
\hline StdOrder & RunOrder & CenterPt & Blocks & NR Pressure & GR Scale & CDS Conv. & Over Length \\
\hline 4 & 1 & 1 & 1 & 1.2 & 7.8 & 0.39 & 0.33 \\
8 & 2 & 1 & 1 & 1.2 & 7.8 & 0.45 & 0.67 \\
13 & 3 & 1 & 1 & 1 & 7 & 0.45 & 0.33 \\
11 & 4 & 1 & 1 & 1 & 7.8 & 0.39 & 0.33 \\
7 & 5 & 1 & 1 & 1 & 7.8 & 0.45 & 0.67 \\
9 & 6 & 1 & 1 & 1 & 7 & 0.39 & 0.17 \\
15 & 7 & 1 & 1 & 1 & 7.8 & 0.45 & 0.67 \\
14 & 8 & 1 & 1 & 1.2 & 7 & 0.45 & 0.67 \\
16 & 9 & 1 & 1 & 1.2 & 7.8 & 0.45 & 0.67 \\
12 & 1 & 1 & 1 & 1.2 & 7.8 & 0.39 & 0.33 \\
1 & 11 & 1 & 1 & 1 & 7 & 0.39 & 0 \\
5 & 12 & 1 & 1 & 1 & 7 & 0.45 & 0.33 \\
3 & 13 & 1 & 1 & 1 & 7.8 & 0.39 & 0.33 \\
6 & 14 & 1 & 1 & 1.2 & 7 & 0.45 & 0.67 \\
10 & 15 & 1 & 1 & 1.2 & 7 & 0.39 & 0.67 \\
2 & 16 & 1 & 1 & 1.2 & 7 & 0.39 & 0.33 \\
\hline
\end{tabular}

Minitab data processing result indicates that R-Square value is $81.2 \%$, which means the independent variables have strong influences on the length of the products (See Fig. 3).
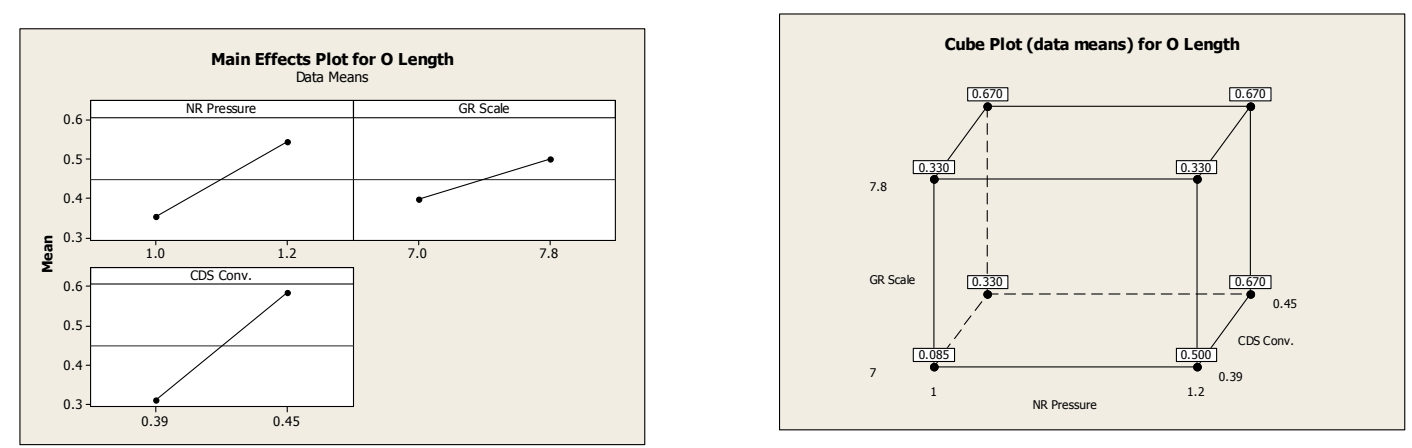

Fig. 3. Design of Experiment in the crimper area 
Main effect plot shows that setting ideal in the crimper experiment for decreasing over length are: (i) NR Pressure is $1.0 \mathrm{~kg} / \mathrm{cm}^{2}$, (ii) GR scale is 7.0 and CDS speed is $0.39 \mathrm{M} / \mathrm{min}$.

\section{Design of Experiment in the Cutter Area}

Independent variable : $\left(\mathrm{X}_{1}\right)$ Cutter and feed roll speed, $\left(\mathrm{X}_{2}\right) \mathrm{H}$ guide and rotor distance, $\left(\mathrm{X}_{3}\right)$ : Press roll and blade distance. Response variable (Y) DPO over length.

Table 8

Design of Experiment Cutter Area

\begin{tabular}{cccccccc}
\hline StdOrder & RunOrder & CenterPt & Blocks & Cutter-FR Speed & H Guide - Rotor & PR Rotor & O Length \\
\hline 12 & 1 & 1 & 1 & H & 15 & 2.75 & 0.33 \\
13 & 2 & 1 & 1 & L & 5 & 3 & 0.33 \\
11 & 3 & 1 & 1 & L & 15 & 2.75 & 0.17 \\
1 & 4 & 1 & 1 & L & 5 & 2.75 & 0 \\
14 & 5 & 1 & 1 & H & 5 & 3 & 0.33 \\
15 & 6 & 1 & 1 & L & 15 & 3 & 0.33 \\
\hline 8 & 7 & 1 & 1 & H & 15 & 3 & 0.67 \\
\hline 9 & 8 & 1 & 1 & L & 5 & 2.75 & 0 \\
16 & 9 & 1 & 1 & H & 15 & 3 & 0.67 \\
6 & 10 & 1 & 1 & H & 5 & 3 & 0.33 \\
10 & 11 & 1 & 1 & H & 5 & 2.75 & 0.17 \\
3 & 12 & 1 & 1 & L & 15 & 2.75 & 0.17 \\
7 & 13 & 1 & 1 & L & 15 & 3 & 0.33 \\
4 & 14 & 1 & 1 & H & 15 & 2.75 & 0.33 \\
\hline 2 & 15 & 1 & 1 & H & 5 & 2.75 & 0.17 \\
\hline 5 & 16 & 1 & 1 & L & 5 & 3 & 0.17 \\
\hline
\end{tabular}

Measurement results using Minitab software yields R-Square of 95.55\%, which means independent variables have strong influence on length of the products. Fig. 4 shows the influence of variable.
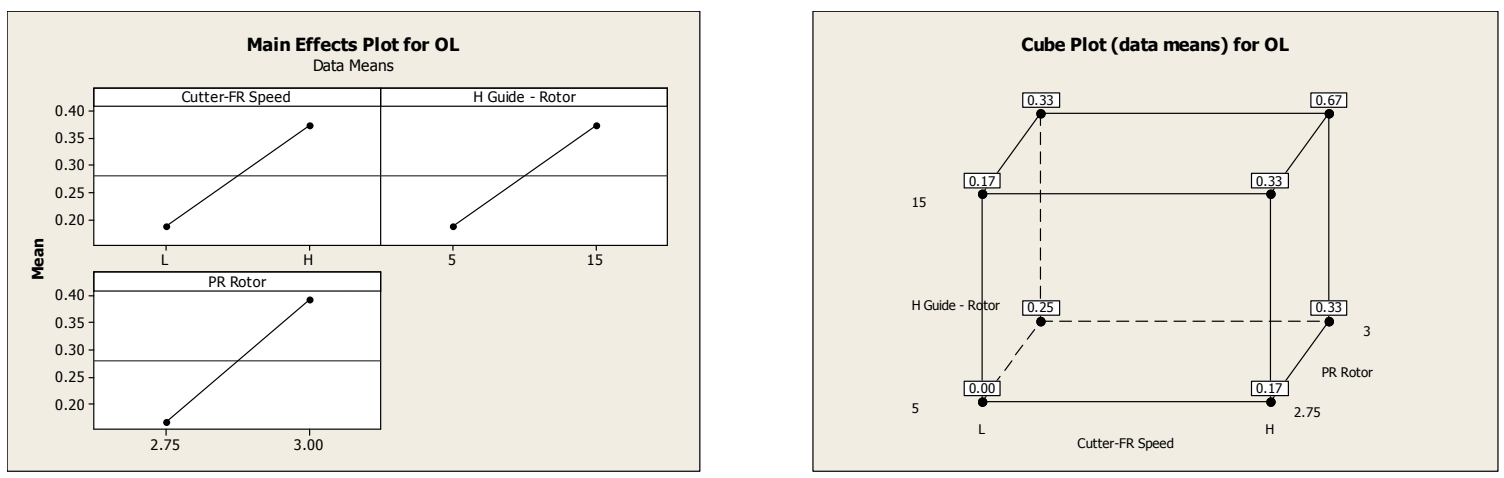

Fig. 4. Design of Experiment in the Cutter Area

Optimum setting from the design experiment are (i) Cutter - FR speed is L (low), (ii) $\mathrm{H}$ guide - rotor distance $5 \mathrm{~mm}$, (iii) press roll - rotor distance is 2.75 scale. 


\subsection{Control}

The result of the experimental implementation of the production process as a parameter setting of the process have shown some improvement with a decreasing sigma level from 2.2 to 3.1 sigma.

\section{Table 9}

Process Capability after Improvement

\begin{tabular}{cccccccc}
\hline Month & OL & Sample & DPO & DPMO & YNA & Zlt & Zst \\
\hline 15-Jun & 164 & 2135 & 0.077 & $76,814.99$ & 0.923 & 1.43 & 2.93 \\
15-Jul & 24 & 1122 & 0.021 & $21,390.37$ & 0.979 & 2.03 & 3.53 \\
15-Aug & 77 & 2000 & 0.039 & $38,500.00$ & 0.962 & 1.77 & 3.27 \\
15-Oct & 72 & 1526 & 0.047 & $47,182.18$ & 0.953 & 1.67 & 3.17 \\
15-Nov & 76 & 820 & 0.093 & $92,682.93$ & 0.907 & 1.32 & 2.82 \\
15-Dec & 101 & 1299 & 0.078 & $77,752.12$ & 0.922 & 1.42 & 2.92 \\
16-Jan & 27 & 626 & 0.043 & $43,130.99$ & 0.957 & 1.72 & 3.22 \\
16-Feb & 73 & 1408 & 0.052 & $51,846.59$ & 0.948 & 1.63 & 3.13 \\
16-Mar & 85 & 1241 & 0.068 & $68,493.15$ & 0.932 & 1.49 & 2.99 \\
16-Apr & 43 & 888 & 0.048 & $48,423.42$ & 0.952 & 1.66 & 3.16 \\
16-May & 24 & 324 & 0.074 & $74,074.07$ & 0.926 & 1.45 & 2.95 \\
\hline Average & 69.64 & $1,217.18$ & 0.058 & $58,208.26$ & 0.942 & 1.6 & 3.1 \\
\hline
\end{tabular}

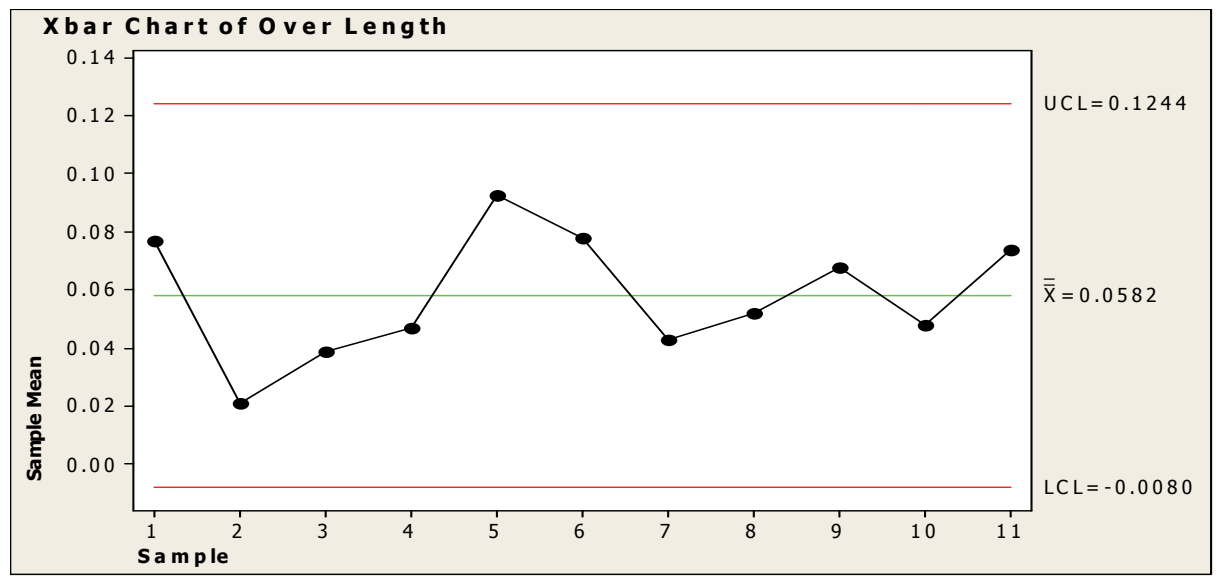

Fig. 5. Process Capability Control Diagram

Position of process capabilities after improvement are shown in the four block diagram (Fig. 5).



Fig. 6. Position of Process Capabilities after Improvement 
If a value of capability process is within quadrant $\mathrm{A}$, it means the problems is strongly related to poor technology and control aspects. The capability process that remains in quadrant B means that the technology is appropriate but less controlling. By contrast, an organization or company within quadrant $\mathrm{C}$ means that it lacks proper implementation of technologies but has appropriate controls to the user. The ideal one is given by the quadrant D (world class), where the capability process related to the technology implementation and control measures are fully integrated (Purba, 2016).

\section{Conclusion}

This paper has presented an empirical investigation to reduce nonconforming products in a texture industry. Over Length was a critical problem causing high rates of nonconforming products. Field check and brainstorming result have resulted seven vital factors: (i) setting of tow passing, (ii) Pressure of PR RS IV, (iii) NR Pressure, (iv) GR scale, (v) conveyor CDS speeds, (vi) cutter and feed roll speed (vii) $\mathrm{H}$ guide and rotor distance, (viii) press roll and rotor distance. Design of experiment has been performed to get an ideal combination setting to reduce the amount of over length. The results have indicated that we could reduce 77.4 percent over length and process capabilities increase from 2.2 sigma to 3.1 sigma. Saving that can be made by this improvement is $\$ 18,394.2$ USD per-month.

\section{References}

Aksoy, B., \& Orbak, Â. Y. (2009). Reducing the quantity of reworked parts in a robotic arc welding process. Quality and Reliability Engineering International, 25(4), 495-512.

Croft, C., \& Kovach, J. V. (2012, January). Reducing Defects in the Production of Natural Gas Dehydration Equipment. In IIE Annual Conference. Proceedings (p. 1). Institute of Industrial EngineersPublisher.

Dambhare, S., Aphale, S., Kakade, K., Thote, T., \& Borade, A. (2013). Productivity improvement of a special purpose machine using DMAIC principles: A case study. Journal of Quality and Reliability Engineering, 2013.

de Jesus Pacheco (2014). Theory of Constraints and Six Sigma: Investigating differences and similarities for continuous improvement. Independent Journal of Management \& Production, 5(2), 331.

Djamaludin, I., Murthy, D. N. P., \& Wilson, R. J. (1994). Quality control through lot sizing for items sold with warranty. International Journal of Production Economics, 33(1), 97-107.

Goettmann, J. A., \& Boylan, J. R. (1992). U.S. Patent No. 5,133,835. Washington, DC: U.S. Patent and Trademark Office.

Kairulazam, C. K., Hussain, M. I., Mohd Zain, Z., \& Lutpi, N. A. (2014). Reduction of rejection rate for high gloss plastics product using six sigma method. In Applied Mechanics and Materials, 606, 141-145.

Ketan, H., \& Nassir, M. (2016). Aluminium hot extrusion process capability improvement using Six Sigma. Advances in Production Engineering \& Management, 11(1), 59.

Kumaravadivel, A., \& Natarajan, U. (2013). Application of six-sigma DMAIC methodology to sandcasting process with response surface methodology. The International Journal of Advanced Manufacturing Technology, 69(5-8), 1403-1420.

Kwak, Y. H., \& Anbari, F. T. (2006). Benefits, obstacles, and future of six sigma approach. Technovation, 26(5), 708-715.

McClusky, R. (2000). Six Sigma Special The rise, fall and revival of six sigma.Measuring Business Excellence, 4(2), 6-17.

Mu, G. Y., Wang, F., \& Mi, X. Z. (2013). Application of Six Sigma DMAIC methodology in welding assembly Quality Improvement. In Applied Mechanics and Materials, 395, 1099-1103.

Nithyanandam, G. K., Raju, M., \& Srinivasan, G. (2014). Defects Reduction in Steering Gear Product Using Six Sigma Methodology. In Applied Mechanics and Materials, 598, 647-651.

Patil, S. D., Ganganallimath, M. M., Math, R. B., \& Karigar, Y. (2015). Application of Six Sigma Method to Reduce Defects in Green Sand Casting Process: A Case Study. International Journal on Recent Technologies in Mechanical and Electrical Engineering (IJRMEE) ISSN, 2349-7947. 
Purba, H. H. (2016). Reducing the operational stop time of Hauller Komatsu Hd465-7 by using the Six Sigma's approach in Pt X. ComTech, 7(2), 91-103.

Rao, S., Nepal, B., \& Yadav, O. P. (2015, January). Productivity Improvement Of Production Floor Using Line Balancing: a Case Study at a Manufacturing Company. In Proceedings of the International Annual Conference of the American Society for Engineering Management. (p. 1). American Society for Engineering Management (ASEM).

Sahoo, A. K., Tiwari, M. K., \& Mileham, A. R. (2008). Six Sigma based approach to optimize radial forging operation variables. Journal of Materials Processing Technology, 202(1), 125-136.

Snee, R. D. (2010). Lean Six Sigma-getting better all the time. International Journal of Lean Six Sigma, 1(1), 9-29.

Soković, M., Pavletić, D., \& Krulčić, E. (2006). Six Sigma process improvements in automotive parts production. Journal of Achievements in Materials and Manufacturing Engineering, 19(1), 96-102.

Sonphuak, W., \& Rojanarowan, N. (2013). Strength improvement of fibre cement product. International Journal of Industrial Engineering Computations, 4(4), 505-516.

Tchidi, M. F., He, Z., \& Li, Y. B. (2012). Process and quality improvement using Six Sigma in construction industry. Journal of Civil Engineering and Management, 18(2), 158-172.

Zare Mehrjerdi, Y. (2011). Six-Sigma: methodology, tools and its future.Assembly Automation, 31(1), 79-88.

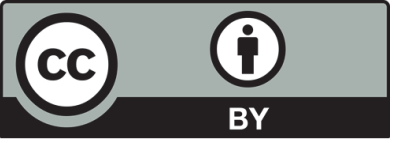

(C) 2017 by the authors; licensee Growing Science, Canada. This is an open access article distributed under the terms and conditions of the Creative Commons Attribution (CC-BY) license (http://creativecommons.org/licenses/by/4.0/). 